\title{
European Portfolio for Student - Teachers of Languages (EPOSTL) and Insights from Student - Teachers' Feedback
}

\author{
Merita Hoxha, PhD Candidate \\ Prof. Dr. Vilma Tafani \\ "A Xhuvani” University, Elbasan, Albania
}

Doi:10.5901/ajis.2015.v4n3p71

\begin{abstract}
This study focuses on some issues: first it gives a general view on portfolios: their usage, form and content and then it focuses on a specific portfolio which is the European Portfolio for Student Teachers of Languages (EPOSTL). This article gives some information about the teaching practice in "Aleksander Xhuvani" University in Elbasan, Albania and then it describes the implementation of EPOSTL in this university. It tries to highlight how EPOSTL helped most of the student-teachers who used it, and it tries to share the experience that the student-teachers and the researchers had while working with EPOSTL and how do student-teachers view the EPOSTL based on their feedback. Through interviews and two questionnaires, one at the beginning of initial teacher education and one after the teaching practice the authors try to answer the following questions: How beneficial is EPOSTL (illustrated with examples, ideas from student-teachers)? How independent do student-teachers feel while working with it? In which ways do student-teachers feel more confident? What is the role of the teachers and mentors regarding EPOSTL? Is there any change in the relation between student-teachers and their mentors resulting from the use of EPOSTL? How is EPOSTL helping the student-teachers change the way they evaluate and self-evaluate? Student-teachers of "A. Xhuvani" University, Elbasan, Albania, have been using EPOSTL for a few years and they bring some interesting and useful insights. EPOSTL is the basic source of training for student-teachers and their feedback helps to draw conclusions concerning the benefits and ways of using it in the future.
\end{abstract}

\section{Literature Review}

Using portfolios in the education system has become a necessity lately. Despite the kind of portfolio one uses portfolios always remain a very effective tool to promote reflection on progress and achievement. Portfolios in education were firstly introduced in late 1980s. Diez (1994) describes portfolios with these metaphors:

- $\quad$ mirror- because of the reflective nature of the portfolio

- map -a tool for planning

- sonnet- within a structure

While Fernsten (2009) mentions that there is a variety of portfolio types each designed for a specific purpose such as assessing either the process or the products of learning. Some of the types of portfolios Fernsten describes are: showcase portfolios, process portfolios, evaluation portfolios and online or e-portfolios.

Barret (2003) suggests that the term "portfolio" should always have a modifier or an adjective that describes its purpose. Some of the types of portfolios she suggests are:

- learning portfolio

- assessment portfolio

- best work portfolio

- $\quad$ marketing portfolio

- employment portfolio

In Albania portfolios started being used in the last two decades. Below is the use of portfolios in our education system.

- K-12 - Pre-school (5 - 6 years old)

- Elementary ( 7 - 15 years old)

- High school (15 - 18 years old)

- Student-teachers (pre-service)

- Probation students

- In-service teachers 
This study is about a portfolio that is being used by student teachers in "Aleksander Xhuvani" University in Elbasan Albania. This portfolio, the European Portfolio for Student Teachers of Languages is in fact a mixture of different types of portfolios. This portfolio is considered as a tool to promote professional growth through reflection and dialogue. (EPOSTL 2008).

Newby (2011) describes EPOSTL as a didactic portfolio which helps to prepare student teachers of modern languages for their future profession by providing a framework for reflection during their teacher education course.

The European Portfolio for Student Teachers of Languages (EPOSTL) is a document intended for students undergoing their initial teacher education which encourages them to reflect on the didactic knowledge and skills necessary to teach languages, helps them to assess their own didactic competences and enables them to monitor their progress and to record their experiences of teaching during the course of their teacher education. Newby (2011)

According to Mueller, (2014) in the more thoughtful portfolio assignments, students are asked to reflect on their work, to engage in self-assessment and goal-setting. Those are two of the most authentic skills students need to develop to successfully manage in the real world. EPOSTL on the other hand mostly aims to achieve these goals: reflection and self-evaluation.

\section{Methodology}

For this study the researchers have used two questionnaires to get both qualitative and quantitative data. By the first questionnaire, which is held every year before the five week teaching practice, the researchers wanted to get a general perception of the student teachers about EPOSTL. They also want to have some data about how many student-teachers have used a similar portfolio before.

By the second survey, which is held at the end of the five week teaching practice, the researchers wanted to have some more specific information about whether EPOSTL helped or not during the teaching practice, some insights and suggestions about its usage.

Last year 38 student-teachers volunteered to be part of the survey. They completed both the questionnaires and were an active part of the discussion sessions which were organized once a week during the teaching practice.

\section{Description}

EPOSTL in "Aleksander Xhuvani" University.

The initial teaching preparation for students of the Master Studies in "A Xhuvani" University is organized in this form:

$>$ First term - 15 weeks, observe 2 classes per week

$>$ Second term -15 weeks, 1 day per week ( 3 classes observation, 1 class teaching at elementary schools

$>$ Third term - 10 weeks, 1 day per week, (3 classes observation, 1 class teaching at elementary schools

$>$ Third term - teaching practice for 5 weeks

As seen from above during the third term (second year of studies) our students go back to 9-year schools for their 5-week active teaching practice, where the students have to teach five days a week for five weeks. This is exactly the time when student-teachers mostly use EPOSTL.

It was 2009 when EPOSTL was firstly introduced in our university. During the years it has got a few drawbacks due to the changes in curricula. Yet we can say that its usage has started to consolidate in the last 4 years. Participating in workshops and conferences organized by ECML, and sharing ideas with people using EPOSTL all around Europe helped the researchers find ways to make students use EPOSTL successfully.

Every year these last 4 years the researchers have conducted a survey with students who started their 5 weeks teaching practice. One of the information they tried to get from the survey was whether the students had ever used a similar portfolio before and around $90 \%$ of them had never used one. This made students think that using EPOSTL was really hard. This was the reason why the researchers decided to introduce the EPOSTL since the beginning of the first year of the Master Studies.

Orlova (2011) reports the experience of student teachers in Czech Republic:

two students were unwilling to reflect on the EPOSTL because they found it difficult to state whether they can do something in class since they had never tried their hand at teaching. After careful consideration, the researcher suggested reformulating the statements from 'I can do....' to 'I think I am prepared/aware how to do.....' 
Taking into consideration that students of the first semester only observe two classes per week and they have never tried teaching the researchers also suggested these students to reformulate the statements to "I think I am prepared to......" instead of "I can..." and to give a look at the descriptors in order to see what is expected from them as future teachers.

The second step of using EPOSTL is during the second semester. Apart from the observation classes our students have Teaching Skills classes. In these classes they deal with methods, techniques, lesson planning, teaching speaking, writing etc which at the same time are part of categories of EPOSTL. During these classes the researchers decided to work with EPOSTL in a different way. Because the students had started teaching, they were asked to use EPOSTL as it is: without reformulating the statements into "I think I am prepared to......". In order to help the students as much as possible during these classes the researchers decided to discuss the descriptors and the usage of the portfolio as in a workshop. Some of the students wanted to share with each other how they completed the bars even though they knew that EPOSTL is a personal portfolio. The researchers were delighted to notice that most of the student-teachers had filled the bars in a truly objective way.

The third moment of using EPOSTL in our university is during the third semester while having the teaching practice. During this time the student-teachers were asked to use EPOSTL the way that worked better for them but advised to fill the bars at least once a week. Once a week the student-teachers and the researchers met together to discuss about the teaching practice in general and also about the use of EPOSTL. In these meetings both students and researchers shared ideas about the use of the portfolio, discussed about descriptors and tried to give their opinion on how to use EPOSTL successfully.

On the other hand, after completing their master studies Albanian students have to complete one year of probation practice. We have encouraged the students to continue using EPOSTL even during this period.

During these years the researchers have had debates and discussions with the students about the EPOSTL and its usage as well as conducted surveys to get feedback and insights from the students. This school-year the researchers have conducted two surveys.

The first survey, as mentioned above was two weeks before the 5-week teaching practice. This survey was mostly focused on students' first impression on EPOSTL, if students had ever used any other portfolio, and what they expected from EPOSTL.

The second survey was about the usefulness and usage of EPOSTL, students' perceptions of EPOSTL, suggestions and insights etc.

This year the researchers also started discussions once a week for the use of EPOSTL and what worked and didn't work during the week of teaching practice. In these discussions students shared ideas about it and suggested how to improve work with EPOSTL in the future. It was noticed that these discussions proved to be useful, so for the future it would be better to organize workshops on using different parts of EPOSTL at least once or twice for semester during theoretical course and every week during the teaching practice.

\section{Results and Discussion}

As mentioned above, the researchers deliver the EPOSTL to the students two weeks before they start their 5- week teaching practice. As it is a personal portfolio first it was thought to give no clues or instructions on how to use it, just to see if they had any idea. The researchers ask the student teachers to look at the Portfolio and to reflect on it. Then, on the first day of their teaching practice students are asked to complete a short questionnaire. Here is the data of the questionnaire.

\subsection{Before EPOSTL have you used any similar portfolio?}

$90 \%$ of the students answered NO. The portfolios that students had used before EPOSTL were best work portfolios or portfolios which intended to show evidence of students' progress and achievement. While EPOSTL focuses mostly on reflection and self-evaluation.

\subsection{What was your first impression of the EPOSTL?}

The answers were different but almost $80 \%$ of the student teachers said that they found it difficult at the beginning. Besides this, here are some other ideas. 
$>$ I thought it was like an "invisible supervisor".

$>$ When I first started using it, I thought "there are some aspects of teaching here which I hadn't thought of before" I also thought it was a good way to measure the extent of my own abilities.

$>$ It was very interesting.

$>$ I like EPOSTL. It is something new for us, something we had no idea that could exist.

$>$ It was a very important tool for reflection and self-assessment.

$>$ It looked like something you could not understand and use without the help of someone who could advice you.

\subsection{What do you expect from EPOSTL?}

At this point most of the students, almost $95 \%$ wrote that they expected EPOSTL to help them in all the teaching process.

$>$ I really hope that EPOSTL would work for me as a mentor or a supervisor.

$>$ I expect EPOSTL to help me identify my strong and weak points during the teaching process.

$>$ I hope EPOSTL could "teach" me how to prepare my lesson plan.

$>$ I hope that this portfolio would help me have a better understanding of what is expected from me as a future teacher

$>$ It's a portfolio. It could be useful in so many ways

Through the above answers the researchers got some very useful feedback. The fact that the student- teachers had not used any similar portfolio before EPOSTL made them think that using EPOSTL would be hard. As mentioned before the researchers did not give any directions on how to use EPOSTL because they wanted to know if studentteachers knew something about portfolios, wanted the students to reflect upon EPOSTL, and did not want to influence their first impressions about it.

The students answers made the researchers think to introduce the EPOSTL since the first semester of the Master Studies and give the necessary instructions on how to use it.

The second survey was conducted at the end of the 5-week teaching practice period. 56 questionnaires were delivered, but only 38 student-teachers handed back the completed questionnaires. The second questionnaire was about the usefulness of EPOSTL, students' perceptions of EPOSTL, etc. The results were impressive and we got some very interesting insights. Following are some of the questions and results of the survey.

1. How independent did you feel while working with EPOSTL?

A. Very independent. I could understand almost all the descriptors and fill the bars easily. $40 \%$

B. Independent. Some of the descriptors were difficult to be understood and I had to discuss about them with my colleagues. $55 \%$

C. Not very independent. I needed my instructor to help me with follow up. 5\%

2. How useful did you find this portfolio?

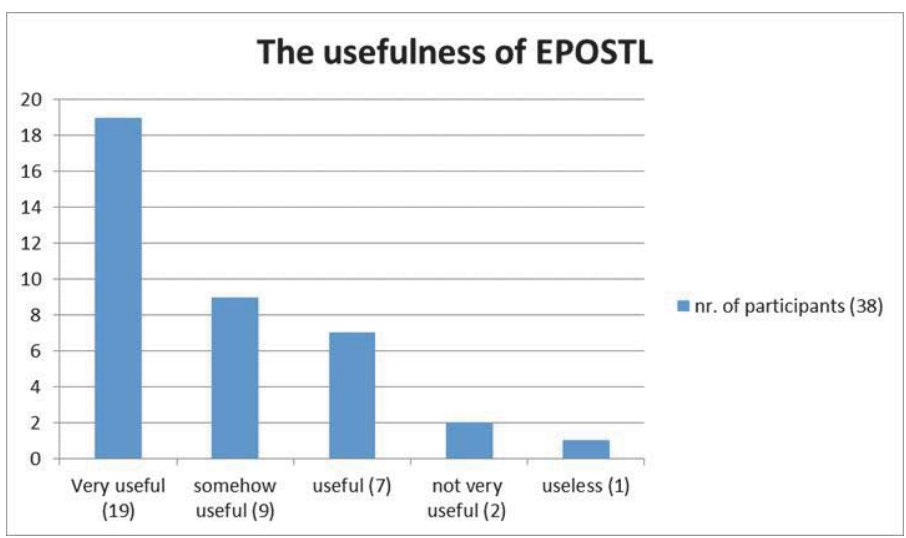

Figure 1. How useful did the students find using EPOSTL during their teaching practice. 


\subsection{Which category of EPOSTL was more useful to you?}

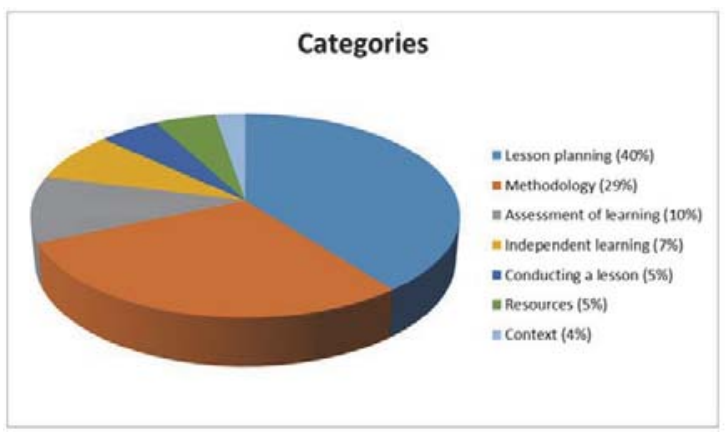

Figure 2. The categories of EPOSTL that were more useful to student teachers during the teaching practice.

As a very important and somehow ambiguous part of their preparation as future teachers, $40 \%$ of the student-teachers mentioned lesson planning as the most useful category of EPOSTL. The researchers think that this high percentage might also be as a result of using EPOSTL while having their teaching practice, thus having to prepare a lesson plan every day.

\subsection{How would you define the knowledge your mentor has about EPOSTL?}

Approximately $50 \%$ of the students wrote that they think their mentors had no knowledge at all about EPOSTL, while $40 \%$ wrote that they had very little knowledge. $10 \%$ of the students wrote their mentors had a considerable knowledge about EPOSTL or knew it very deeply.

At this point we may say that unfortunately EPOSTL didn't help student teachers to strengthen the relation with their mentors.

\subsection{Do you agree or disagree with the following statements:}

1. The EPOSTL made me think of different aspects of teacher education.

2. The EPOSTL helped me to understand what competences a teacher of foreign languages should have.

3. The EPOSTL made me aware of the competences I have developed, on learner autonomy as well as those I still need to develop.

4. The EPOSTL helped me trace my progress.

5. The EPOSTL is a good instrument for the self-assessment and peer assessment.

6. The EPOSTL is a useful teaching and learning device.

7. The Albanian student teachers will benefit by using EPOSTL regularly.

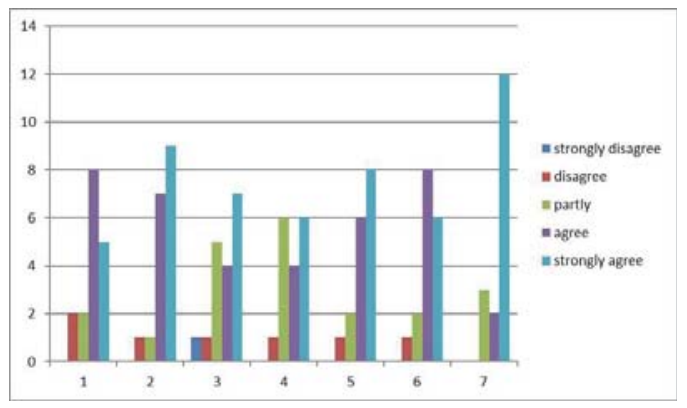

Figure 3. Do you agree or disagree with these statements. 
4.7 Do you think EPOSTL is helping you to change the way you evaluate and/or self-evaluate? If "yes" please mention how?

Almost all the 38 students that participated in the survey wrote "Yes", EPOSTL was helping them to change the way they evaluate and/or self-evaluate. As evaluation and self-evaluation in Albania is a cultural issue, which means that rather we underestimate (undervalue) or overestimate (overvalue) others and even ourselves, EPOSTL is a tool to help us evaluate/self-evaluate objectively. Students consider it as a tool which helps them identify exactly their abilities and lack of abilities in the teaching process.

- Yes. Well since it helps me know specifically where my abilities are lacking, it also helped me to focus on improving these aspects by periodically working on them.

- Yes. I think that EPOSTL helped me to change and have the right opinion about myself. Firstly I was confused about my capacity in teaching, but then EPOSTL helped me to evaluate myself objectively.

- Yes. It is very useful, it is a guide which helps you in every step of your teaching process.

- Yes. By using EPOSTL I am able to self-evaluate and to correct what I did wrong. I can see what is ok with my teaching methods and what should be changed.

\section{In a Few Sentences Write your Opinion about EPOSTL}

Our students' opinions about EPOSTL were different but deep inside they had a lot in common. Most of the students consider it very useful and helpful for all the teaching and learning process.

- It is very useful for student-teachers and it helps us to improve our teaching skills.

- I I think for us it's still a work in progress. I haven't been able to use it much because it's time consuming and it takes time to using it as well. I think it's necessary to some students.

- EPOSTL is very useful to teachers. It makes their job easier and helps them to organize the lesson. It gives them a chance to acquire new methods of teaching not just using the old traditional methods

- I think that EPOSTL helps teachers in their profession. It helps you to get prepared and to evaluate yourself. When you use EPOSTL you can have everything under control because it helps and prepares you in everything.

- EPOSTL is a good way to keep track of your own skills, meaning how much you have advanced during a period of time compared to the previous time you used EPOSTL. Also it is very useful in making you aware of what you are lacking as a future teacher. If used correctly it can help you become a better teacher.

- EPOSTL has helped me to evaluate myself and to see the changes that I had since the beginning till now. I consider it as a consultant that gives me advices.

- It is very useful, it helps me in all the teaching progress.

- EPOSTL is something new for us as students. I like it because it is very practical and helps us.

- A guide that every student-teacher, teacher or mentor should have in order to be more effective in their profession.

- It is a guide for us as student teachers as we have no experience.

\subsection{Do you have any suggestions for the use of EPOSTL?}

Although our students found it difficult to use EPOSTL at the beginning most of them reported that they got used to it; they could understand most of the descriptors and use it independently. They considered it useful and helpful and had no suggestions for EPOSTL as a portfolio. Nevertheless they had some suggestions for its usage and the other students who are going to use EPOSTL in the future.

- I think it is very useful the way it is.

- No, everything is crystal clear.

- I suggest that all the mentors could use it also. As students we should use it because it is helpful for us to understand in which category we have deeper knowledge and in which we should be more capable.

- I think it ought to go straight to the point. When you see it for the first time the arrows and everything it looks pretty confusing and also takes away your desire to work with it.

- In fact I don't have any suggestions for EPOSTL itself, but I have some suggestions for the students working with it. I would suggest other students that while working with EPOSTL not to neglect the areas you thought/ 
were more confident about and only focus on the ones you were lacking. I would also suggest students to work with EPOSTL periodically and regularly.

- I think EPOSTL should be more popular in Albania and all the people that deal with teaching and learning a foreign language possess it. Students should be encouraged to work with it more often.

\section{Conclusions}

By the results of both the surveys the researchers came to these conclusions.

First, at the beginning most of the students found it difficult to use EPOSTL. Some of them did not feel very independent and they needed to consult their mentors, colleagues, or lecturers for some of the descriptors. But, the results of the second survey indicate that besides the first difficulties most of the students got used to it by using EPOSTL regularly.

Second, after using EPOSTL for 5 weeks during the teaching practice most of the students, almost $50 \%$ declared they found it very useful and helpful.

Third, students wrote in the survey that they think their mentors do not have enough knowledge about EPOSTL. They say that they consider their mentors' knowledge as limited. They find this fact as problematic because in this way they do not have any possibilities to collaborate with their mentors about the use of EPOSTL.

\section{References}

Barret. H (2003) http://www.electronicportfolios.com/ALI/research.html.

Council of Europe, (2007). European Portfolio for Student Teachers of Languages,http://www.coe.int

Little, D. (2000). Why focus on learning rather than teaching: Council of Europe.

Little, D. (2002). The European Language Portfolio and learner autonomy: Council of Europe Publishing.

Newby D et al (2007) European Portfolio for Student Teachers of Languages- A reflection tool for language teacher education. Council of Europe Publishing.

Newby D. et al. (2011), Using the European Portfolio for Student Teachers of Languages; Council of Europe, Austria, ECML Publications (A collection of articles).

Newby D . et al. (2012) Insights into the European Portfolio for Student Teachers of Languages (EPOSTL) Cambridge Scholars Publishing.

Mueller J (2014) Authentic Assignment Toolbox http://jfmueller.faculty.noctrl.edu/toolbox/portfolios.htm\#reflection.

Orlova N (2011) Challenges of integrating the EPOSTL into pre-service teacher training Council of Europe Publishing. 
